\title{
A case of associated thyrotoxicosis and phaeochromocytoma. A diagnostic problem
}

\author{
M. H. SNOW \\ M.B., M.R.C.P.
}

\author{
P. Burton \\ M.B., Ch.B., D.Obst., R.C.O.G., M.R.C.Path.
}

Newcastle General Hospital

\begin{abstract}
Summary
A case of phaeochromocytoma and thyrotoxicosis occurring in the same patient is described, in which the similarity between the signs and symptoms produced by the two conditions delayed full diagnosis until post mortem. The mechanisms involved in the production of these signs and symptoms are discussed.
\end{abstract}

\section{Introduction}

This case of thyrotoxicosis associated with a malignant phaeochromocytoma is reported to emphasize the similarity between the clinical features of the two diseases. The persistence of the sympathomimetic features of thyrotoxicosis, despite adequate antithyroid therapy, was attributed to inconsistent taking of medication, and the diagnosis of phaeochromocytoma was made only at post-mortem.

\section{Case presentation}

A 28-year-old housewife with two children had symptoms of anxiety for 1 year before she presented with features of thyrotoxicosis. These included recent weight-loss of $12.71 \mathrm{~kg}$ despite a normal appetite, palpitations, exertional dyspnoea and heat intolerance. There was no history of headaches and the only revelant family history was that her mother died of a cerebral haemorrhage in her forties.

Examination revealed hyperkinesis and fine finger tremor, slight generalized thyroid enlargement, bilateral lid retraction together with slight proptosis of the right eye, regular tachycardia, a warm skin and excessive sweating. Blood pressure was 130/75 $\mathrm{mmHg}$, heart sounds were normal and there was no retinopathy.

The diagnostic index score was +36 (Crooks, Murray and Wayne, 1959), euthyroid patients scoring less than 11.

The clinical diagnosis was confirmed by a PBI of $11.0 \mathrm{mg} / 100 \mathrm{ml}$ (normal range $4-8 \mathrm{mg} / 100 \mathrm{ml}$ ); $\mathrm{T}_{3}$

Correspondence: Dr M. H. Snow, Department of Medicine, Wellcome Research Laboratory, Royal Victoria Infirmary, Newcastle upon Tyne NE1 4LP. resin uptake 125 (normal range 82-128) giving a free $\vec{\omega}$ thyroxine index of $13 \cdot 8$ (normal range $2 \cdot 2-7 \cdot 1$ ).

Twenty minute thyroid uptake of intravenous 3 ${ }^{132}$ I was high at $20 \%$ (normal less than $8 \%$ ). Thyroid ${ }^{\circ}$. antibodies and long acting thyroid stimulator? LATS were not detected in her serum and a TSHO level was $2.4 \mathrm{~m} \mu / \mathrm{ml}$ (normal 0.5-4.0 $\mathrm{m} \mu / \mathrm{ml}$ ).

Treatment was begun with carbimazole $40 \mathrm{mg} \mathrm{N}_{\infty}^{\infty}$ daily in divided doses reducing after 2 months to 30 o $\mathrm{mg}$ daily. She became clinically euthyroid only after ${ }_{-}$ continuing this relatively high maintenance dose for 3 6 months.

At this time she became pregnant, aborting in the $\overrightarrow{-}$ first trimester and her blood pressure was recorded at $160 / 90 \mathrm{mmHg}$.

Six months later, whilst on the same antithyrofdo regime she began her fourth pregnancy, which wats associated with a rapidly increasing exophthalmico ophthalmoplegia.

During the 22nd week of this pregnancy she was $\stackrel{\mathbb{2}}{2}$ admitted with a small ante-partum haemorrhage $\overrightarrow{\vec{O}}$ and a blood pressure of $150 / 90 \mathrm{mmHg}$. The bleeding 3 stopped and the hypertension settled with bed rest.

During the latter half of her pregnancy she? reported a severe panic attack with headache ando tachycardia but when seen her blood pressure was.again only $150 / 90 \mathrm{mmHg}$ and the attack was thought $\frac{}{3}$ to have been psychogenic. Shortly before term a normal child was delivered vaginally and a few days 윽 later sterilization by tubal ligation was carried out.

During the recovery phase from this operation the $\frac{\text { ? }}{3}$ blood pressure rose to $210 / 150 \mathrm{mmHg}$ but settled rapidly following administration of a 'lytic cocktail' consisting of pethidine $100 \mathrm{mg}$, promazine $50 \mathrm{mg}$ and N promethazine hydrochloride $50 \mathrm{mg}$.

Following delivery her thyrotoxicosis was controlled on $20 \mathrm{mg}$ of carbimazole but a relapse with $\mathrm{W}$ tachycardia, heat intolerance and tremor, necessitated an increase to $40 \mathrm{mg}$ daily. Despite thise relatively large dose of carbimazole, with a normal PBI and $T_{3}$ resin uptake she continued to have ${ }^{-}$ apparent relapses which coincided with domestic $\frac{0}{0}$ crises and were attributed to inconsistent taking of her medication. 


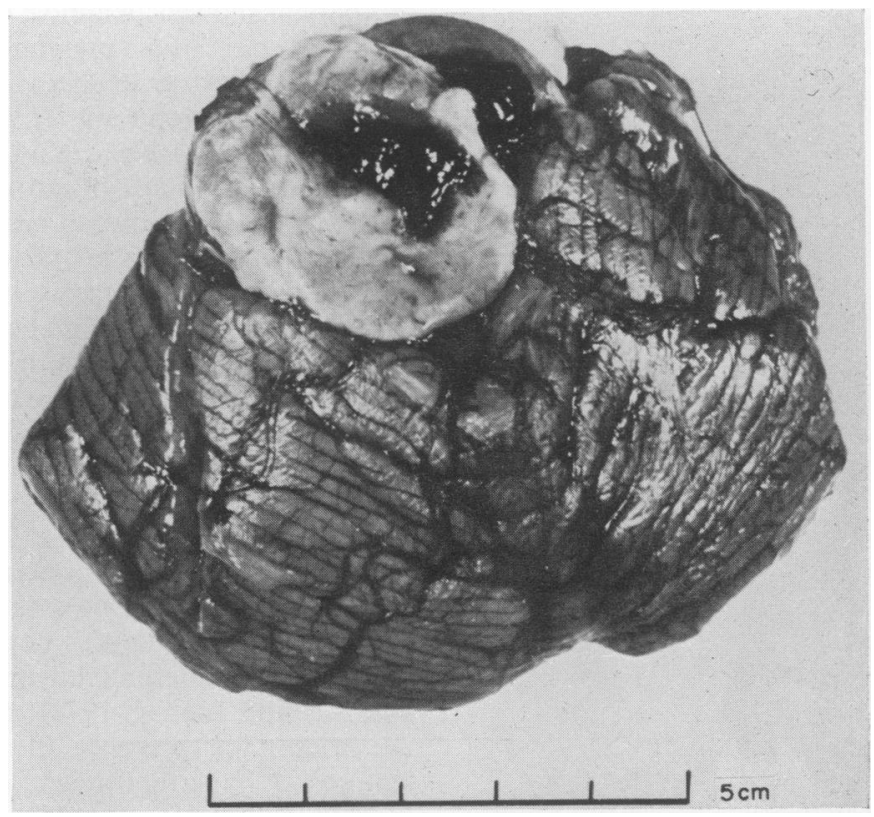

FIG. 1. Right-sided pontine haemorrhage.

At this stage she required a myomectomy for the severe exophthalmic ophthalmoplegia; there were no complications during or after this operation.

Two and a half years after her initial presentation, the patient was admitted as an emergency with a right lower neurone facial weakness and a left hemiparesis of sudden onset.

Lumbar puncture revealed evenly blood stained cerebrospinal fluid and she was thought to have had a pontine haemorrhage.

Initially she was alert and orientated with a pulse rate of $96 / \mathrm{min}$ and a $\mathrm{BP}$ of $210 / 100$. After $48 \mathrm{hr}$, she developed a pyrexia and an increasing tachycardia, with a pulse rate of $180 / \mathrm{min}$. Thyrotoxic crises and septicaemia were considered as causes and she was given Lugol's iodine and propranolol together with antibiotics. The tachycardia was controlled, but circulatory collapse supervened and she died $72 \mathrm{hr}$ after admission.

At post-mortem she was noted to have many pigmented naevi on the thorax and gross exophthalmos. A large, recent, right-sided pontine haemorrhage was present with cerebellar tonsillar herniation (Fig. 1).

A large haemorrhagic, brown tumour (145 g) replaced the left adrenal, and a single small metastasis was present in the liver (Fig. 2). Both tumours had the characteristic histological appearance and staining reactions of a phaeochromocytoma. Extensive quantities of depleted brown adipose tissue were noted around the kidneys, adrenals and in the mediastinum. The heart weighed $310 \mathrm{~g}$ and showed left ventricular hypertrophy. The thyroid (weight $13.5 \mathrm{~g}$ ) showed some diversity of acinar size but no histological features of thyrotoxicosis or thyroiditis.

\section{Discussion}

Phaeochromocytoma is known to occur in association with medullary carcinoma of the thyroid (Ljundberg, Cederqvist and Standnitz, 1967; Sipple, 1961; Williams and Pollock, 1966); but in this patient the association with thyrotoxicosis was probably fortuitous.

The clinical features of thyrotoxicosis can be explained partly by the direct action of the thyroid hormones on the tissues (Wollerburger, 1965; Buccino et al., 1967), and in part by over-activity of the sympathetic nervous system.

The mechanism of this over-activity is uncertain; urinary catecholamine excretion products are normal in hyperthyroidism (Wiswell et al., 1963). Although $\beta$-adrenergic blockade by propranolol reduces the heart rate and cardiac output at rest (Howitt and Rowlands, 1966), it has a quantitatively similar reaction in simple anxiety states (Tumer, Granville-Grossman and Smart, 1965). Other features of thyrotoxicosis improved by this drug include palpitation, heat intolerance, tremor and warm skin (Shanks et al., 1969), but it does not reduce the raised oxygen consumption (Howitt and Rowlands, 1966).

These sympathomimetic features are common to 


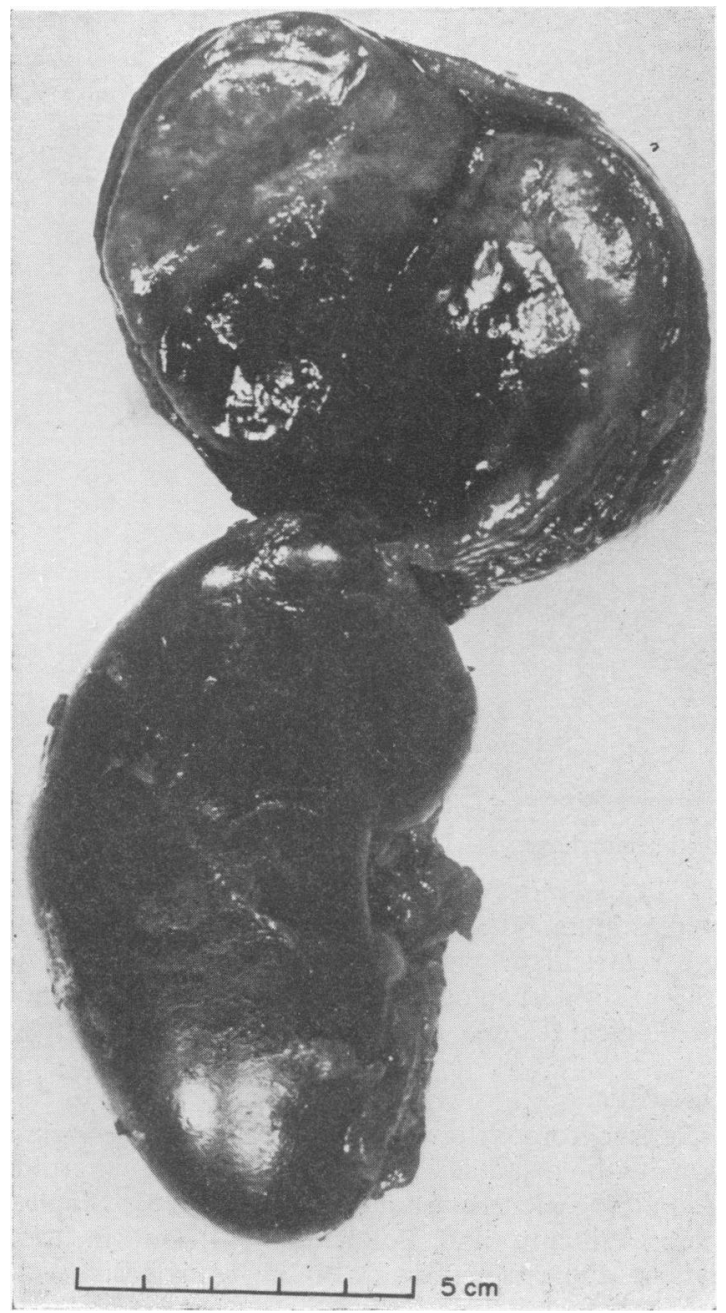

Fig. 2. Large left phaeochromocytoma replacing the adrenal.

both thyrotoxicosis and phaeochromocytoma. In patients with a phaeochromocytoma, serum protein bound iodine, rate of release and uptake of ${ }^{131} \mathrm{I}$, and rate of clearance of labelled $T_{3}$ or $T_{4}$ are usually within the normal range (Harrison, 1964) and it is therefore unlikely that the catecholamines have a significant direct effect on thyroid function in man.

The increased heat production and oxygen consumption in both thyrotoxicosis and phaeochromocytoma may be related to the increased metabolism of fat (Goodman and Bray, 1966; Engleman, Mueller and Sjoerdsma, 1964) which may be stimulated by the synergistic activity of noradrenaline and thyroid hormones (Leblanc, 1970). This synergistic effect is easily seen in the metabolism of the thermogenetic brown adipose tissue which in this patient showed an almost complete loss of stored fat. This has been previously reported in both $\frac{2}{3}$ phaeochromocytoma (Sherwin, 1959) and in thyro- $\stackrel{\mathbb{Q}}{\odot}$ toxicosis (Hammond and Hamolsky, 1969).

It is well recognized that phaeochromocytoma requires a high index of suspicion for its diagnosis $\stackrel{?}{\rightarrow}$ and that the presenting symptomatology is also varied. The diagnosis of phaeochromocytoma in a 음 patient with thyrotoxicosis is particularly difficult $\frac{\bar{\sigma}}{\sigma}$ because of their overlapping clinical features.

Thyroid swelling occurs in $6 \%$ of patients with a phaeochromocytoma and can be induced experi- $\vec{\circ}$ mentally by infusion of noradrenaline (Herman and Momex, 1964). Moreover, only about $50 \%$ of $\vec{\omega}$ patients (Gifford et al., 1964) with a phaeochromo- $\frac{}{\circ}$ cytoma exhibit continuous hypertension; indeed, $\stackrel{0}{7}$ rarely the patient may present with postural hypotension (Parkinson, 1964).

Phaeochromocytoma is not invariably considered in the clinical differential diagnosis of thyrotoxicosis (Werner and Ingbar, 1971); this case suggests that ${ }_{\infty}$ the continuing presence of the sympathomimetic ${ }_{\circ}^{\infty}$ features of hyperthyroidism, despite adequate anti- $\frac{}{\square}$ thyroid medication, should prompt the clinician to $\vec{z}$ consider the possibility of an associated phaeochromocytoma.

\section{Acknowledgments}

We wish to thank Dr F. Clark for his encouragement and permission to publish details of a patient under his care and Mrs M. E. Shephard for secretarial help.

\section{References}

Buccino, R.A., SPann, J.F., Pool, P.E., Sonnenblick, E.H. $\overrightarrow{\vec{\rho}}$ \& BRAUNWALD, E. (1967) Influence of the thyroid state on the intrinsic contractile properties and energy stores of the myocardium. Journal of Clinical Investigation, 46, 1669.

Crooks, J., MurRaY, I.P.C. \& WAYNE, E.J. (1959) Statistical methods applied to the clinical diagnosis of thyrotoxicosis. Quarterly Journal of Medicine, 28, 211.

Engleman, K., Mueller, P.S. \& SJoerdsma, A. (1964) Elevated plasma free fatty acid concentrations in patients with phaeochromocytoma. New England Journal of Medicine, 270, 865 .

Gifford, R.W., KVAlE, W.F., MahoR, T.T., Roth, G.M. \& Priestley, J.T. (1964) Clinical features, diagnosis and treatment of phaeochromocytoma, a review of 76 cases. Proceedings. Mayo Clinic, 39, 281.

GOODMAN, H.M. \& BRAY, G.A. (1966) Role of thyroid hormones in lypolysis. American Journal of Physiology, 210, 1053.

Hammond, R.P. \& Hamolsky, M.W. (1969) Thyroidcatecholamine interaction. Studies on isolated brown fat cells. Physiologist, 12, 246.

HARRISON, T.S. (1964) Adrenal medullary and thyroid $\sigma$ relationships. Physiological Reviews, 44, 161.

Herman, H. \& MOMEX, R. (1964) Human Tumours Secreting Catecholamines. Pergamon Press, Oxford.

HowITT, G. \& Rowlands, D.J. (1966) B sympathetic $\stackrel{\mathscr{D}}{+}$ blockade in hyperthyroidism. Lancet, i, 628.

LeBlanc, J. (1970) Hormonal control of thermogenesis. Nonshivering thermogenesis. Symposium, Prague, 1970, pp. 99. Academia, Prague. 
LuUndberg, O., Cederqvist, E. \& Standnitz, W. von (1967) Medullary thyroid carcinoma and phaeochromocytoma: a familial chromaffinomatosis. British Medical Journal, 1, 279.

Parkinson, T. (1964) Phaeochromocytoma presenting as postural hypotension. Proceedings of the Royal Society of Medicine, 57, 673.

Shanks, R.G., Hadden, D.R., Lowe, D.G.C., McDevitT, D.G. \& MONTGOMERY, D.A.D. (1969) Controlled trial of propranolol in thyrotoxicosis. Lancet, i, 993.

SHERWIN, R.P. (1959) Histopathology of phaeochromocytoma. Cancer, 12, 861.

SIPPLE, J.H. (1961) The association of phaeochromocytoma with carcinoma of the thyroid gland. American Journal of Medicine, 31, 163.
Tumer, P., Granville-Grossman, K.L. \& Smart, J.V. (1965) Effect of adrenergic receptor blockade on the tachycardia of thyrotoxicosis and anxiety. Lancet, ii, 1316.

WERNER, S.C. \& INGBAR, S.H. (1971) The Thyroid, 3rd Edition, p. 496. Harper and Rowe, New York.

Williams, E.D. \& Pollock, D.J. (1966) Multiple mucosal neuromata with endocrine tumours, a syndrome allied to von Reklinghausen's disease. Journal of Pathology and Bacteriology, 91, 71.

Wiswell, J.G., HuRwitz, G.C., CoRonho, V., Bing, O.H.L. \& CHILD, D.L. (1963) Urinary catecholamines and their metabolites in hyper and hypo-thyroidism. Journal of Clinical Endocrinology, 23, 1102.

WOLLERBURGER, A. (1965) Current topics in thyroid research (Ed. by D. C. Casson and M. Andreoli), p. 377. Academic Press, Inc., New York.

\title{
Arterial surgery in pseudoxanthoma elasticum
}

\author{
D. J. CARTER \\ M.R.C.P.
}

\author{
F. P. VINCE \\ M.R.C.P.
}

\author{
D. A. K. WOODWARD \\ F.R.C.S.
}

Walsgrave Hospital, Coventry

\begin{abstract}
Summary
A 25-year-old female with pseudoxanthoma elasticum was referred with disabling ischaemia in one lower limb. She had suffered from peripheral vascular disease from the age of 15. Reconstructive arterial surgery was successful.
\end{abstract}

\section{Case report}

A 25-year-old female was referred in 1973 with a history of ulceration of the left foot for 3 months, with severe pain at rest. Walking had become too painful to attempt. Pseudoxanthoma elasticum had been diagnosed at the age of 7 on the basis of classical skin changes. She had suffered from intermittent claudication in both calves for at least 10 years. A haematemesis had occurred in 1967. She became thyrotoxic in 1972 and was treated with carbimazole. On referral in 1973 she was euthyroid. Skin changes of pseudoxanthoma elasticum were present, particularly involving the sides of the neck. Angioid streaks were seen on fundoscopy. The lower limbs were wasted. The peripheral pulses were absent below the femorals. A painful ulcer, $3 \times 2.5 \mathrm{~cm}$, was present on the dorsum of the left foot, and a smaller

Correspondence: Dr D. J. Carter, Department of Medicine, Walsgrave Hospital, Coventry CV2 2DX. ulcer was noted on the medial malleolus of the same foot. She was normotensive and an electrocardiogram was normal.

A lumbar sympathectomy was performed but there was no improvement. A left femoral arteriogram showed small calibre vessels and occlusion of the left femoral artery in its distal third. There was good filling of the popliteal artery via collaterals (Fig. 1). Femoropopliteal by-pass grafting was therefore carried out. At operation the left femoral artery was very small but patent. It was dissected free below the origin of the profunda femoris artery and a length of reversed autogenous saphenous vein was sutured, end to side, proximally to the top end of the superficial femoral artery and distally to the popliteal artery which was of wider calibre than the femoral. Both arteries took sutures normally. Postoperatively there was a return of the peripheral pulses in the left leg. Pain was relieved and the ulcer gradually healed. Twelve months later full recovery in the limb was maintained.

\section{Discussion}

Pseudoxanthoma elasticum is a genetically determined, probably autosomal recessive, disorder. A number of recent studies (Moran and Lansing, 1958; 